\title{
Т.К. ВОЛКОВИЧ
}

\section{СКВАМОЗНАЯ НЕОПЛАЗИЯ ГЛАЗНОЙ ПОВЕРХНОСТИ}

ГУО «Белорусская медицинская академия последипломного образования», г. Минск,

\author{
Республика Беларусь
}

В статье представлен литературный обзор, посвященный изучению особенностей эпидемиологии, патогенеза, диагностики и лечения сквамозной неоплазии глазной поверхности (СНГП). Частота заболеваемости в различных странах мира значимо варьирует - от 0,03 до 3,5 случаев на 100000 населения. Наиболее значимыми и изученными причинами развития новообразований глазной поверхности являются солнечная инсоляция, вирус папилломы человека, вирус иммунодефицита человека.

Вариабельность клинической картины требует правильной дифференциальной диагностики, так как течение СНГП часто маскируется под дистрофические заболевания конъюнктивы (пингвекула, птеригиум), васкуляризованные помутнения роговицы, а так же может проявлять себя как меланома или невус. Трудности дифференциальной диагностики с учетом данных клинического осмотра обуславливают необходимость применения высокотехнологичных методов исследования (оптическая когерентная томография переднего отрезка глаза) и обязательной морфологической диагностики (цитологическая и гистологическая диагностика).

Лечение СНГП включает различные терапевтические и хирургические подходы, а чаще их комбинацию - хирургическое удаление новообразования и применение цитостатиков или препаратов интерферона, однако не учитывает этиологию заболевания. Частота рецидива СНГП остается по-прежнему высокой - от 10 до 56\% случаев в зависимости от характера роста, объема хирургического вмешательства и продолжительности послеоперационного ведения пациентов.

Представляется актуальным дальнейшее изучение этиологии и патогенеза сквамозной неоплазии глазной поверхности, а так же разработка комплексных подходов в диагностике и лечении с учетом этиологии заболевания.

Ключевые слова: роговица, конбюнктива, глазная поверхность, сквамозная неоллазия, новообразование, частота заболеваемости, этиология заболевания

The article presents a scientific literature review devoted to studying the features of epidemiology, pathogenesis, diagnosis and treatment of ocular surface squamous neoplasia (OSSN). In different countries morbidity rate varies significantly from 0,03 to 3,5 cases per 100000 population. The most important and studied causes of ocular surface neoplasia development are considered to be solar insolation, human papilloma virus, human immunodeficiency virus.

Variability of the clinical picture requires the proper differential diagnostics, since OSSN often masks as degenerative diseases of the conjunctiva (pinguecula, pterygium), vascularized corneal opacity, and can also manifest itself as melanoma or nevus.

Difficulties in the differential diagnostics based on clinical examination data necessitate the usage of high-tech research methods (optical coherence tomography of the ocular anterior segment) and the obligatory morphological diagnostics (cytological and histological diagnosis). Treatment of OSSN includes various medical and surgical approaches, more often their combination - surgical removal of tumors or usage of cytostatics or the medication interferon without taking into consideration the etiology. The high recurrence rate of OSSN is still remained - 10$56 \%$ of cases depending on the growth type, volume of surgery and duration of postoperative care of patients.

It is relevant to further studying the etiology and pathogenesis of ocular surface squamous neoplasia, as well as the development of integrated approaches in diagnosis and treatment taking into account the etiology of disease.

Keywords: cornea, conjunctiva, ocular surface, squamous neoplasia, neoplasm, morbidity rate, etiology of the disease

Novosti Khirurgii. 2015 Jul-Aug; Vol 23 (4): 460-466

Ocular Surface Squamous Neoplasia

T.K. Volkovich

\section{Терминология}

Поверхность глазного яблока представлена конъюнктивой и роговицей. Новообразования данной локализации являются наиболее частыми среди опухолей органа зрения. Их, как и все новообразования, подразделяют на доброкачественные и злокачественные, врожденные и приобретенные. Отдельного вни- мания заслуживают опухоли эпителиального происхождения. По данным М.A. Saornil et al. [1], на их долю приходится до $40 \%$ новообразований поверхности глазного яблока, 64,5\% из которых были диагностированы как состояние «предрак».

До 1995 г не было единой терминологии для заболеваний данной группы. Поэтому до этого периода в литературе встречаются раз- 
личные названия: интраэпителиальная эпителиома, интраэпителиальная неоплазия и дисплазия, болезнь Боуэна, эпителиома Боуэна, сквамозная папиллома [2].

В 1995 году G.A. Lee и L.W. Hirst был предложен термин «Сквамозная неоплазия глазной поверхности» (ocular surface squamous neoplasia - OSSN), объединяющий заболевания, сопровождающиеся патологической пролиферацией эпителия роговицы и/или конъюнктивы глазного яблока (от простой гиперплазии до инвазивной сквамозно-клеточной карциномы) [2]. Этот термин включает в себя как гиперплазию и дисплазию, так и карциномy in situ и сквамозно-клеточную карциному эпителия [2, 3].

\section{Эпидемиология}

Заболеваемость сквамозной неоплазией глазной поверхности (СНГП) значительно варьирует и географически обусловлена. Так, наиболее часто - 3,5 случаев на 100000 населения - СНГП встречается у лиц, проживающих в экваториально расположенных странах, 1,9 случаев на 100000 населения в Австралии и значительно реже в странах с умеренным и субарктическим климатом, например, в северных районах Соединенных Штатов Америки - 0,03 случая на 100000 населения [2]. По данным A. Maudgil et al. [4] 79\% заболевших были лица кавказского происхождения.

Сквамозная неоплазия глазной поверхности встречается в любом возрасте и у лиц обоих полов. В настоящее время нет единого мнения в отношении возрастного пика заболеваемости и половой предрасположенности. Так, по данным ряда авторов среди заболевших преобладают мужчины $(78,5 \%, 77 \%, 70 \%$ и $71 \%$ случаев соответственно) средний возраст которых был более 60 лет [2, 4, 5, 6, 7]. Напротив, исследования Е.C. Pola et al. [8] свидетельствуют о том, что СНГП достоверно чаще встречается у женщин (70\%) в возрасте около 35 лет. Подобные данные получили A. Mahomed и R. Chetty в 2002г. - средний возраст заболевших составил 37 лет [9]. Согласно исследованиям K. Toopalli et al., опубликованным в 2014 году, СНГП развивается чаще у мужчин (60\%) в возрасте 46 лет (min$\max 7-85)[10]$.

\section{Классификация}

В настоящее время применяют классификацию СНГП, предложенную G.A. Lee и L.W. Hirst, учитывающую клинический и морфологический характер заболевания [2]:

I. Доброкачественная дисплазия:

- Папиллома;

- Псевдотелиоматозная гиперплазия;

- Доброкачественный врожденный интраэпителиальный дискератоз.

II. Преинвазивная сквамозная неоплазия глазной поверхности:

- Карцинома in situ роговицы и/или конъюнктивы.

III. Инвазивная сквамозная неоплазия глазной поверхности:

- Сквамозная карцинома;

- Мукоэпидермоидная карцинома

\section{Этиология и патогенез}

В этиологии развития сквамозной неоплазии глазной поверхности выделяют несколько причин [2]:

- наиболее значимые - солнечная инсоляция, вирус папилломы человека, вирус иммунодефицита человека;

- другие (иммуносупрессивная терапия, возраст, работа и/или проживание в загрязненной среде, синдром лимбальной недостаточности).

Солнечная инсоляция. Солнечной инсоляции, а именно, спектру ультрафиолетового излучения (290-320 nm) отводится главная роль в развитии СНГП [11], что, по-видимому, объясняет более высокую частоту развития заболевания в экваториально расположенных странах. Преимущественной локализацией новообразования в таких случаях является область открытой глазной щели [2]. Иммуногистохимические исследования J. Ng et al. [12] показали, что ультрафиолетовое излучение оказывает стимулирующее действие на выработку протеолитических ферментов, в большей степени матричной металлопротеиназы и ее ингибиторов, которые определяются в высокой концентрации у пациентов с неоплазией глазной поверхности.

Вирус папилломы человека (ВПЧ) является онкогенным вирусом. Наиболее частой мишенью для данного вируса является шейка матки [13, 14]. По данным Y. Nakamura et al. [13], около $50 \%$ случаев новообразований поверхности глазного яблока и слезного мешка были папилломавирусной этиологии. Согласно ряду исследований, наиболее часто новообразования вызывают 16 и 18 типы вируса, $[13,14,15,16]$. Исследования, проведенные V. V. Verma et al. [16] в 2008 г., показали, что в норме в конъюнктиве глазного яблока могут определяться ВПЧ 6 и 11 типов, а 16 и 
18 типы только у пациентов со СНГП. Напротив, согласно данным Z.A. Karcioglu и T.M. Issa [17], последние обнаруживаются как в норме, так и при патологии. В исследованиях C. Ateenyi-Agaba et al. [18] ВПЧ определялся в $86 \%$ случаях СНГП и в $35 \%$ - без признаков заболевания.

Вирус иммунодефицита человека (ВИЧ). Сквамозная неоплазия глазной поверхности зачастую является одним из первых признаков манифестации ВИЧ инфекции [19, 20]. По данным K.M. Waddell et al. [21], сквамозная неоплазия конъюнктивы определялась в $71 \%$ случаев ВИЧ инфицированных пациентов, причем, отличалась более агрессивным течением: быстрым ростом и высоким риском малигнизации [22]. Кроме того, у таких пациентов сквамозная неоплазия может развиваться не только на глазной поверхности, но и поражать шейку матки, ротоглоточную или аноректальную зону [23]. Иммуногистохимические исследования удаленного материала у ВИЧ инфицированных пациентов по поводу СНГП выявили мультифакториальную природу новообразования. Так, в гистологических срезах определялись такие онкогенные вирусы как вирус папилломы человека, ЭпштейнаБарр и саркомы Капоши [24].

Другие причины развития сквамозной неоплазии глазной поверхности. Определенную роль в развитии СНГП отводят иммуносупрессии, при которой повышается восприимчивость в ВПЧ. Т.Н. Flynn et al. [25] описали случай развития конъюнктивальной интраэпителиальной неоплазии 3 степени у пациентки с тяжелым атопическим дерматитом и кератоконъюнктивитом, после системного и местного лечения циклоспорином.

Ряд исследователей сообщили о случаях развития заболевания на фоне иммуносупрессивной терапии у пациентов после трансплантации донорских органов и тканей [26, 27]. Данные A. Ramasubramanian et al. [28] свидетельствуют о том, что неопластические клетки могут содержаться в донорской роговице и могут в последующем приводить к развитию СНГП.

Другими причинами развития СНПГ являются возраст (чем старше человек, тем выше частота заболевания), наличие гиперпигментации кожи или эписклеры, курение, длительное пребывание в загрязненной среде (например, работа на нефтеперерабатывающих производствах) [2, 29, 30]. Так же возможной причиной заболевания является ношение глазного протеза или контактных линз, однако достоверных доказательств этому нет [31, 32].

\section{Клиника}

Клиническая картина сквамозной неоплазии глазной поверхности зависит от локализации и характера роста образования [7]. Размер, цвет, форма и характер роста могут быть вариабельны в каждом случае. Симптомы не специфичны. Так, течение заболевания может сопровождаться выраженным болевым синдромом, чувством инородного тела, блефароспазмом, гиперемией, снижением остроты зрения. Вместе с тем, жалобы могут полностью отсутствовать.

Сквамозную неоплазию конъюнктивы или конъюнктивальную интраэпителиальную неоплазию подразделяют на две формы: нодулярную (узловая) и диффузную. Диффузная форма на ранних стадиях сложна в диагностике, так как зачастую протекает как хронический конъюнктивит [2, 15]. Наиболее частой локализацией является проекция открытой глазной щели или конъюнктива сводов. Лимбальная локализация, как правило, сопровождается вовлечением в патологический процесс роговицы. При расположении у внутреннего лимба новообразование может быть клинически подобным на такие дегенеративные заболевания конъюнктивы как пингвекула или птеригиум, а при роговичном вовлечении может симулировать паннус [33]. Кроме того, оно может быть пигментировано и мимикрировать как меланома [34].

Сквамозная неоплазия роговицы изолированно встречается редко, в большинстве случаев она развивается одномоментно с конъюнктивальной [2]. Так же как и конъюнктивальная неоплазия, чаще всего развивается в проекции открытой глазной шели. В отличие от смешанных форм изолированная сквамозная неоплазия роговицы отличается агрессивным ростом.

Отдельного внимания заслуживает сквамозно-клеточная карцинома, рост которой может происходить за пределы базальной мембраны конъюнктивы и/или роговицы. На практике только по клиническим признакам достаточно сложно отличить интраэпителиальный рост от инвазивного. Для точной диагностики необходимо проведение инструментальных и морфологических методов исследований. В случаях интраокулярной инвазии могут развиваться такие осложнения как иридоциклит, вторичная глаукома, отслойка сетчатки [7].

\section{Дифференциальная диагностика}

Дифференциальную диагностику сквамоз- 
ной неоплазии глазной поверхности проводят с заболеваниями роговицы и конъюнктивы, сопровождающимися патологическим ростом эпителия и новообразованных сосудов [35]:

- Паннус

- Дефицит витамина А

- Начальный интраэпителиальный дискератоз

- Пингвекула

- Птеригиум

- Пиогенная гранулема

- Кератоакантома

- Псевдотелиоматозная гиперплазия

- Невус и меланома

\section{Диагностика}

Выбор тактики лечения пациентов со сквамозной неоплазией глазной поверхности зависит от правильно проведенной диагностики, определения причины заболевания, характера роста и результатов морфологического исследования. Так, в диагностике СНПГ применяют методы наружного осмотра, биомикроскопии, ультразвуковой биомикроскопии (УБМ), оптической когерентной томографии переднего отрезка глаза, гониоскопии, компьютерной и магнитно-резонансной томографии (КТ и МРТ), а так же иммунологические, иммуногистохимические и морфологические методы исследования (цитология поверхности глазного яблока, биопсия новообразования, гистологическое исследование удаленного материала) [36].

При наружном осмотре и при биомикроскопии уделяют внимание локализации образования (роговица, конъюнктива, лимб), характеру роста (диффузный, локальный, узелковый, поверхностный или инвазивный), определяют возможное склеральное вовлечение (подвижность образования), учитывают цвет (пигментированное или беспигментное), форму (гладкая или мелкозернистая), наличие сосудов в самом образовании и состояние приводящих питающих сосудов [2, 3].

Оптическая когерентная томография (ОКТ) переднего отрезка глаза позволяет определить характер роста (интраэпителиальный или инвазивный), ориентировочную протяженность и глубину инвазии новообразования в строму роговицы. ОКТ, УБМ и гониоскопия дают возможность оценить вовлечение в патологический процесс структур угла передней камеры [36]. КТ и МРТ применяют с целью диагностики распространения опухоли в орбиту.

Гистологический анализ биопсии или уда- ленного образования является обязательным в выборе тактики лечения пациента. Он основан на определении выраженности диспластических изменений в клетках, глубине поражения, оценке ядерно-цитоплазматического отношения, наличии сквамозных клеток с гиперхромными ядрами и патологических митозов в исследуемом материале [37, 38].

Выраженность морфологических изменений определяет характер СНГП [37, 38]:

- Дисплазия: наличие диспластически измененных клеток и глубина интраэпителиального вовлечения определяют степень дисплазии:

○ слабая - менее чем 1/3 толщины интраэпителиальных изменений;

○ умеренная - не более $3 / 4$ толщины интраэпителиальных изменений;

○ тяжелая/Карцинома in situ - патологический процесс определяется на всем протяжении эпителия без вовлечения базальной мембраны.

- Инвазивная сквамозноклеточная карцинома - опухолевые клетки проникают через базальную мембрану.

Цитологическое исследование поверхности глазного яблока при СНГП выполняют двумя способами - соскоб поверхности новообразования тупым шпатлем или цитощеткой и методом импрессионной цитологии. Изменения эпителия, обнаруживаемые при цитологии, были описаны G.A. Lee и L.W. Hirst в 1995 г. [2]:

- дисплазия;

- карцинома in situ;

- инвазивная сквамозноклеточная карцинома.

\section{Лечение}

В настоящее время существует множество терапевтических и хирургических подходов в лечении СНГП. Наиболее распространенным подходом является полное удаление образования в пределах неизмененных тканях с применением спиртовой кератоэпителийэктомии и послойной склерокератоконъюнктивоэктомии и последующей криотерапии техникой двойной заморозки [7]. Хирургическое лечение может быть дополнено местной химиотерапией - цитостатиками [39, 40]. Дефект тканей после удаления образования закрывают амниотической мембраной или слизистой губы. В случаях инвазивного интрастромального роста прибегают к сквозным керато- или склерокератопластикам [41]. При интраокулярном росте образования выполняют сквозную локаль- 
ную резекцию, а при интраорбитальном распространении - объем оперативного лечения может быть расширен вплоть до экзентерации орбиты [7].

С целью хеморедукции опухоли перед операцией или реже как основной подход в лечении местно проводят химиотерапию с использованием митомицина С, 5-фторурацила [39, $42,43,44]$. Чаще их применяют в качестве адъювантной терапии рецидивов СНГП. Однако применение цитотоксических препаратов зачастую сопряжено с такими осложнениями как эпителиопатия, склеромаляция, поражение кластеров лимбальных стволовых клеток и, как следствие, лимбальная недостаточность [45].

B качестве местной иммунотерапии достаточно широкое применение имеет интерферон-альфа-2b. По данным A. Sturges et al. [46] он эффективен в лечении первичной СНГП. Исходы лечения могут быть сопоставимы с хирургической тактикой. Так же данный препарат показал хорошие результаты в терапии рецидивирующих форм, а так же в случаях неэффективности митомицина С [47].

\section{Рецидив сквамозной неоплазии глазной поверхности}

Сквамозная неоплазия глазной поверхности характеризуется высокой частотой рецидивов, которая растет с увеличением продолжительности срока наблюдения. Так, в исследованиях A. Galor et al. [48] частота рецидива через 1 год наблюдения составила $10 \%$ и $21 \%$ спустя 5 лет. Подобные данные получили А. Maudgil et al. [4] 10,9\% и 18,5\% соответственно в те же сроки наблюдения. При этом частоту рецидива связывают с характером роста СНГП. В случаях инвазивной сквамозноклеточной карциномы частота рецидива была выше $-27 \%$, тогда как в случаях конъюнктивальной интраэпителиальной неоплазии почти в 3 раза меньше $-10 \%$.

Кроме того, рецидивы связаны с объемом хирургического лечения. Так, при полном удалении образования их частота варьирует от $5 \%$ до 33\%, тогда как в случая обнаружения опухолевых клеток по краю отсечения - достигает 56\% [49].

\section{Заключение}

Проведенный обзор выявил ряд актуальных вопросов, которые нуждаются в дальнейшем изучении. Так, остается открытым вопрос о роли герпесвирусной инфекции в развитии и течении сквамозной неоплазии глазной поверх- ности. Кроме того, в доступной литературе мы не обнаружили данных о проведении этиотропной терапии в случаях подтвержденной инфекционной природы заболевания, за исключением ВИЧ-инфицированных пациентов.

Имеющиеся хирургические подходы в лечении сквамозной неоплазии глазной поверхности не учитывают состояние эпителия глазной поверхности в зонах без клинически видимых изменений.

Таким образом, дальнейшее изучение этиологии и патогенеза сквамозной неоплазии глазной поверхности, а так же разработка комплексных подходов в диагностике и лечении с учетом этиологии заболевания являются необходимыми и социально значимыми.

\section{ЛИТЕРАТУРА}

1. Conjunctival tumors / M. A. Saornil [et al.] // Arch Soc Esp Oftalmol. - 2009 Jan. - Vol. 84, N 1. - P. 7-22. [Conjunctival tumors] [Article in Spanish]

2. Lee G. A. Ocular surface squamous neoplasia / G. A. Lee, L. W. Hirst // Surv Ophthalmol. - 1995 May-Jun. - Vol. 39, N 6. - P. 429-50.

3. Basti S. Ocular surface squamous neoplasia: a review / S. Basti, M. S. Macsai // Cornea. - 2003 Oct. - Vol. 22, N 7. - P. 687-704.

4. Ocular surface squamous neoplasia: analysis of 78 cases from a UK ocular oncology centre / A. Maudgil [et al.] // Br J ophthalmol. - 2013 Dec. - Vol. 97, N 12. - P. 1520-24. doi: 10.1136/bjophthalmol-2013-303338. 5. Squamous cell carcinoma of the conjunctiva: a series of 26 cases / P. A. McKelvie [et al.] // Br J Ophthalmol. - 2002 Feb. - Vol. 86, N 2. - P. 168-73.

6. Lee G. A. Retrospective study of ocular surface squamous neoplasia / G. A. Lee, L. W. Hirst // Aust N Z J Ophthalmol. - 1997 Nov. - Vol. 25, N 4. - P. 269-76. 7. Mittal R. Ocular surface squamous neoplasia - Review of etio-pathogenesis and an update on clinic-pathological diagnosis / R. Mittal, S. Rath, G. K. Vemugati // Saudi J Ophthalmol. - 2013 Jul. - Vol. 27, N 3. - P. 177-86. doi: 10.1016/j.sjopt.2013.07.002.

8. Pola E. C. The trend of ocular surface squamous neoplasia among ocular surface tumour biopsies submitted for histology from Sekuru Kaguvi Eye Unit, Harare between 1996 and 2000 / E. C. Pola, R. Masanganise, S. Rusakaniko // Cent Afr J Med. - 2003 Jan-Feb. - Vol. 49, N 1-2. - P. 1-4.

9. Mahomed A. Human immunodeficiency virus infection, Bcl-2, p53 protein, and Ki-6 analysis in ocular surface squamous neoplasia / A. Mahomed, R. Chetty // Arch Ophthalmol. - 2002 May. - Vol. 120, N 5. P. 554-58.

10. Ocular surface squamous neoplasia impression cytology V/S histopathology / K. Toopalli [et al.] // Sch J App Med Sci. - 2014. - Vol. 2, N 1D. - P. 461-65.

11. Risk factors for conjunctival squamous cell neoplasia: a matched case-control study / W. Tulwatana [et al.] // Br J Ophthalmol. - 2003 Apr. - Vol. 87, N 4. - P. 396-98. 
12. Ultraviolet radiation and the role of matrix metalloproteinases in the pathogenesis of ocular surface squamous neoplasia / J. Ng [et al.] // Invest Ophthalmol Vis Sci. - 2008 Dec. - Vol. 49, N 12. - P. 5295-306. doi: 10.1167/iovs.08-1988.

13. Detection of human papillomavirus infection in squamous tumors of the conjunctiva and lacrimal sac by immunohistochemistry, in situ hybridization, and polymerase chain reaction / Y. Nakamura [et al.] // Br J Ophthalmol. - 1997 Apr. - Vol. 81, N 4. - P. 308-13. 14. Scott I. U. Human papillomavirus 16 and 18 expression in conjunctival intraepithelial neoplasia / I. U. Scott, C. L. Karp, G. J. Nuovo // Ophthalmology. 2002 Mar. - Vol. 109, N 3. - P. 542-47.

15. Giaconi J. A. Current treatment options for conjunctival and corneal intraepithelial neoplasia / J. A. Giaconi, C. L. Karp // Ocular Surface. - 2003 Apr. Vol. 1, N 2. - P. 66-73.

16. The role of infectious agents in the etiology of ocular adnexal neoplasia / V. Verma [et al.] // Surv Ophthalmol. - 2008 Jul-Aug. - Vol. 53, N 4. - P. 312-31. doi: 10.1016/j.survophthal.2008.04.008.

17. Karcioglu Z. A. Human papillomavirus in neoplastic and non-neoplastic conditions of the external eye / Z A. Karcioglu, T. M. Issa // Br J Ophthalmol. - 1997 Jul. - Vol. 81, N 7. - P. 595-98.

18. Epidermodysplasia verruciformis human papillomavirus types and carcinoma of the conjunctiva: a pilot study / C. Ateenyi-Agaba [et al.] // Br J Cancer. - 2004 May 4. - Vol. 90, N 9. - P. 1777-79.

19. Porges Y. Prevalence of HIV with conjunctival squamous cell neoplasia in an African provincial hospital / Y. Porges, G. M. Groisman // Cornea. - 2003 Jan. Vol. 22, N 1. - P. 1-4.

20. Ocular surface squamous neoplasia as the first apparent manifestation of HIV infection in Malawi / M. S. Spitzer [et al.] // Clin Experiment Ophthalmol. - 2008 Jul. - Vol. 36, N 5. - P. 422-25.

21. Carcinoma of the conjunctiva and HIV infection in Uganda and Malawi / K. M. Waddell [et al.] // Br J Ophthalmol. - 1996 Jun. - Vol. 80, N 6. - P. 503-508. 22. The epidemiology of conjunctival squamous carcinoma in Uganda / R. Newton [et al.] // Br J Cancer. - 2002 Jul 29. - Vol. 87, N 3. - P. 301-308.

23. Anterior segment and external ocular disorders associated with human immunodeficiency virus disease / B. H. Jeng [et al.] // Surv Ophthalmol. - 2007 Jul-Aug. - Vol. 52, N 4. - P. 329-368.

24. Multiple oncogenic viruses identified in Ocular surface squamous neoplasia in HIV-1 patients. Infect / K. O. Simbiri [et al.] // Infect Agent Cancer. - 2010 Mar 26. - Vol. 5. - P. 6. doi: 10.1186/1750-9378-5-6.

25. Flynn T. H. Ocular surface squamous neoplasia in an immunosuppressed patient with atopic keratoconjunctivitis / T. H. Flynn, B. Manzouri, S. J. Tuft // Int Ophthalmol. - 2012 Oct. - Vol. 32, N 5. - P. 471-73. 26. Ocular surface squamous neoplasia in a renal transplant recipient on immunosuppressive therapy / D. Shome [et al.] // Eye (Lond). - 2006 Dec. - Vol. 20, N 12 - P. 1413-14.

27. Aggressive conjunctival squamous cell carcinoma in a patient following liver transplantation / A. E. Shelil [et al.] // Arch Ophthalmol. - 2003 Feb. - Vol. 121. - P. 280-82.

28. Ocular surface squamous neoplasia after corneal graft / A. Ramasubramanian [et al.] // Am J Ophthalmol. 2010. - Vol. 149, N 1. - P. 62-65. doi: 10.1016/j. ajo.2009.07.026.

29. Sun E. C. Epidemiology of squamous cell conjunctival cancer / E. C. Sun, T. R. Fears, J. J. Goedert // Cancer Epidemiol Biomarkers Prev. - 1997 Feb. - Vol. 6, N 2. - P. 73-77.

30. Factors associated with conjunctival intraepithelial neoplasia: a case control study / C. Napora [et al.] // Ophthalmic Surg. - 1990 Jan. - Vol. 21, N 1. - P. 27-30.

31. Jain R. K. Conjunctival squamous cell carcinoma due to ocular prostheses: a case report and review of literature / R. K. Jain, R. Mehta, S. Badve // Pathol Oncol Research. - 2010 Dec. - Vol. 16, N 4. - P. 609-12. doi: 10.1007/s12253-010-9251-0.

32. Guex-Crosier Y. Presumed corneal intraepithelial neoplasia associated with contact lens wear and intense ultraviolet light exposure / Y. Guex-Crosier, C. P. Herbort // Br J Ophthalmol. - 1993 Mar. - Vol. 77, N 3. - P. 191-92.

33. Hirst L. W. Pterygium and associate ocular surface squamous neoplasia / L. W Hirst, R. A. Axelsen, I. Schwab // Arch Ophthalmology. - 2009 Jan. - Vol. 127, N 1. - P. 31-32. doi: 10.1001/archophthalmol.2008.531.

34. Pigmented squamous cell carcinoma in situ of the conjunctiva in 5 cases / C. L. Shields [et al.] // Ophthalmology. - 2008 Oct. - Vol. 115, N 10. - P. 167378. doi: 10.1016/j.ophtha.2008.01.020.

35. Ocular surface squamous neoplasia [Electronic resource] / S. Gupta [et al.] // Delhi J Ophthalmol. - 2013. - Vol. 23. - P. 89-96. - Mode of access: http://dx.doi.org/10.7869/djo.2012.49. - Date of access: 25.09 .15 .

36. Mondal S. K. Fine-needle aspiration cytology and scrape cytology of conjunctival squamous cell carcinoma: report of a rare case / S. K. Mondal // Clin Cancer Investig J. - 2015. - Vol. 4, Is. 1. - P. 78-80. doi: 10.4103/2278-0513.149056.

37. Font R. L. Tumors of the conjunctiva and caruncle / R. L. Font, J. O. Croxatto, N. A. Rao // Tumors of the eye and ocular adnexa. AFIP Atlas of tumor pathology. - Washington, DC : Armed Forces Institute of Pathology, 2006. - P. 7-10.

38. Possible prognostic markers in conjunctival dysplasia and squamous cell carcinoma / S. Aoki [et al.] // Jpn J Opthalmol. - 1998 Jul-Aug. - Vol. 42, N 4. - P. 256-61.

39. Dudney B. W. Limbal stem cell deficiency following topical mitomycin $\mathrm{C}$ treatment of conjunctival-corneal intraepithelial neoplasia / B. W. Dudney, M. A. Malecha // Am J Ophthalmol. - 2004 May. - Vol. 137, N 5. - P. 950-51.

40. Khong J. J. Complications of mitomycin C therapy in 100 eyes with ocular surface neoplasia / J. J. Khong, J. Muecke // Br J Ophthalmol. - 2006 Jul. - Vol. 90. - P. 819-22.

41. Penetrating sclerokeratoplasty in massive reccurent 
invasive squamous cell carcinoma / A. Roy [et al.] // Ophthal Plast Reconstr Surg. - 2011 Mar-Apr. - Vol. 27, N 2. - P. e39-40. doi: 10.1097/IOP.0b013e3181eea1d4. 42. Tear function and ocular surface changes with topiintraephitelial neoplasia / M. Dogru [et al.] // Cornea. - 2003 Oct. - Vol. 22, N 7. - P. 627-39.

43. Frucht-Pery J. Mitomycin C therapy for corneal intraepithelial neoplasia / J. Frucht-Pery, Y. Rozenmam // Am J Ophthalmol. - 1994 Feb 15. - Vol. 117, N 2. - P. 164-68.

44. Huerva V. Topical interferon alfa- $2 b$ or surgical excision for primary treatment of conjunctiva-cornea intraepithelial neoplasia / V. Huerva // Arch Soc Esp Oftalmol. - 2009 Jan. - Vol. 84, N 1. - P. 5-6. [Article in Spanish]

45. Khong J. J. Complications of mitomycin C therapy in 100 eyes with ocular surface neoplasia / J. J. Khong, J. Muecke // Br J Ophthalmol. - 2006 Jul. - Vol. 90, N 7. - P. 819-22.

46. Topical interferon or surgical excision for the management of primary ocular surface squamous neoplasia / A. Sturges [et al.] // Ophthalmology. - 2008 Aug. - Vol. 115, N 8. - P. 1297-302. doi: 10.1016/j.ophtha.2008.01.006. cal mitomycin (MMC) treatment for primary corneal

47. Holcombe D. J. Topical interferon alfa-2b for the treatment of recalcitrant ocular surface squamous neoplasia / D. J. Holcombe, G. A. Lee // Am J Ophthalmol. - 2006 Oct. - Vol. 142, N 4. - P. $568-71$.

48. Predictors of ocular surface squamous neoplasia recurrence after excisional surgery / A. Galor [et al.] // Ophthalmology. - 2012 Oct. - Vol. 119, N 10. - P. 1974-81. doi: 10.1016/j.ophtha.2012.04.022.

49. Giant ocular surface squamous neoplasia managed with interferon alfa- $2 b$ as immunotherapy or immunoreduction / H. J. Kim [et al.] // Ophthalmology. - 2012 May. - Vol. 119, N 5. - P. 938-44. doi: 10.1016/j. ophtha.2011.11.035.

\section{Адрес для корреспонденции}

220013, Республика Беларусь,

г. Минск, ул. П. Бровки, д. 3, корп. 3, ГУО «Белорусская медицинская академия последипломного образования», кафедра офтальмологии, тел. моб. +375 447949610 , e-mail: t.volkovich@rambler.ru, Волкович Татьяна Казимировна

\section{Сведения об авторах}

Волкович T.K., к.м.н, доцент кафедры офтальмопоследипломного образования». 